\title{
A man whose scapula was spared a drug-associated rash
}

$\mathrm{A}$ 49-year-old man had been well until advanced lung carcinoma with mediastinal spread and contralateral lung metastases was diagnosed. He received chemotherapy (cisplatin, gemcitabine, vinorelbine), and the progression of disease was temporarily halted. However, he began to experience severe pain in his right shoulder that was only partially relieved by opioids. As there was no evidence of musculoskeletal injury, bone metastases or tumour spread into the brachial plexus, a mediastinal infiltration of the phrenic nerve was suspected. He was given palliative radiation (10 fractions of $3 \mathrm{~Gy}$ ) directed at the area (Fig. 1), which relieved the pain. Four months later, he was given gefitinib as part of his ongoing chemotherapy treatment. After 4 weeks, a progressive rash resembling acne developed on his face and torso. Strangely, the area over his right scapula was spared the eruption (Fig. 2). This area coincided with the area that had received the radia$\approx$ tion therapy.

Gefitinib is a well-tolerated new protein-tyrosine kinase inhibitor with recognized activity in nonsmall-cell lung cancer. One of its most frequent side effects is an acneiform rash on the face and torso, which appears in $25 \%-40 \%$ of patients. ${ }^{1}$ This rash is thought to be related to excessive follicular hyperkeratosis, follicular plugging, obstruction of the follicular ostium and alteration of the hair cycle, which lead to sebaceous hypersecretion and an inflammatory response. ${ }^{2}$ Local radiation is known to induce atrophy in sebaceous glands; external radiotherapy was once used to treat acne vulgaris but was abandoned because of subsequent radiationinduced tumours. The sebaceous gland atrophy caused by local radiation therapy explains why this area of our patient's skin was spared the gefitinibinduced rash.

\section{Álvaro Sanz}

María Luisa del Valle

Oncology Department

Hospital Clínico Universitario

Valladolid, Spain

\section{References}

1. Fukuoka M, Yano S, Giaccone G, Tamura T, Nakagawa K, Douillard $\mathrm{JY}$, et al. Multi-institutional randomized phase II trial of gefitinib for previously treated patients with advanced non-small-cell lung cancer. 7 Clin Oncol 2003;21:2237-46.

2. Lee MW, Seo CW, Kim SW, Yang HJ, Lee HW, Choi JH, et al. Cutaneous side effects in non-small cell lung cancer patients treated with Iressa (ZD1839), an inhibitor of epidermal growth factor. Acta Derm Venereol 2004;84:23-6.
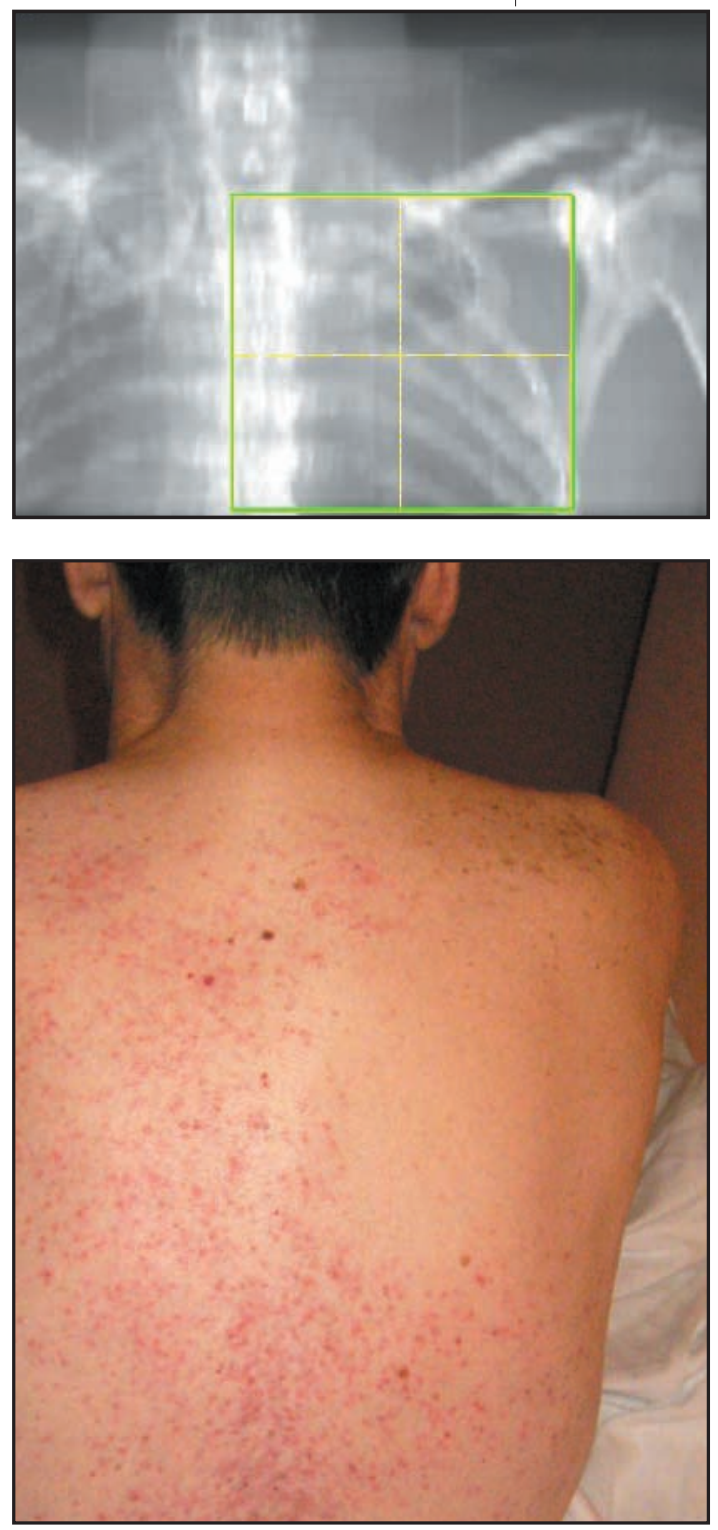